\title{
Aspectos fenológicos, ecológicos \\ e de produtividade da sorva (Couma utilis Muell. Arg.) (1)
}

\author{
Martha de Aguiar Falcão ${ }^{2}$ ) \\ Eduardo Lleras ( ${ }^{3}$ )
}

\section{Resumo}

São aqui apresentados aspectos da fenologia, ecologia e de produtividade da Sorva (Couma utilis Muell Arg.). Em Manaus, a espécie floresce e inicia a frutificaçảo na época mais chuvosa com a safra no período seco. Foram encontradas onze espécies de insetos visitantes, sendo dez Apiidae e uma Heliconiidae. Postula-se a não existência de um polinizador especifico para a espécie. O número de flores variou entre 21.000 a 47.000 para as dez árvores com uma taxa de formação de frutos entre 10 e $15 \%$. Foram encontradas correlaçōes muito altas entre o número de flores e outros parâmetros de produção tais como número de frutos verdes, frutos maduros e peso da safra, o que sugere que outros fatores além dos polinizadores podem desempenhar papel importante na determinação da safra.

\section{INTRODUÇÃo}

Dando seqüência à série de trabalhos sobre fruteiras da Amazônia tanto nativas quanto cultivadas, iniciadas com o Umari e o Mapati (Falcăo \& Lleras, $1980 \mathrm{a}$ e b) apresentamos aqui um estudo da sorva (Couma utilis Muell Arg. ) .

Visa-se, neste trabaiho, como nos anteriores, a contribuir para o conhecimento de aspectos da biologia de fruteiras na Amazônia com $\sigma$ intuito de estabelєcer parâmetros que conccrram para a cultura e melhoramento das mesmas.

\section{MATERIAL E MÉTODOS}

Foram escolhidas 10 árvores de Couma utilis Muell. Arg. (sorva) no sítio Rosa de Maio, Estrada IManaus-Itacoatiara $\mathrm{Km} 8$.

A amostra da espécie em estudo encontrase no herbário do INPA com o $n^{\circ}$ de registro
66.432, Col. Martha de Aguiar Falcăo nọ 189, onde foi identificada por comparação. As observações de campo foram realizadas no período de fevereiro de 1977 a agosto de 1978, semanalmente. Vale ressaitar que as datas estimadas quanto ao início e término dos períodos fenológicos não podem ser ditas exatas porque estas foram consideradas conforme os dias de visitas no campo.

Durante o período de floração, foram esco. Ihidos 3 galhos ao acaso em cada árvore, nos quais se fez a contagem das inflorescências e flores; com a finalidade de estimar-se a quantidade de inflorescências e flores produzidas por árvore, foram contados todos os galhos.

A fim de ter-se uma idéia de se as flores eram ou não autofecundadas, foram envolvidas 10 intlorescências de cada árvore com saquinhos de filó ou morim, dando um total de $10 \mathrm{C}$ inflorescências cobertas.

Foi feito o estudo do pólen encontrado nas patas dos insetos visitantes com o objetivo de fazer-se uma comparação com o pólen da espécie visitada, numa tentativa de determinar-se o polinizador ou polinizadores. Em ambos os casos, o método de preparação do pólen foi o da acetólise (Erdtman, 1960) seguido da montagem de grãos em gelatina glicerinada.

Para estabelecer-se uma correlação entre a freqüência dos insetos nas árvores e a quan. tidade de pólen que eles carregavam foi feita a contagem padrão de 1.000 grãos de pólen por amostra.

Para determinarem-se os possiveis polinizadores de cada espécie, todos os insetos que visitavam as flores foram coletados, acondicionados e identificados pelo Dr. Norman Penny

(1) - Este trabalho é parte da Tese de Mestrado do primeiro autor.

(2) - Fundaçāo Universidade do Amazonas, Manaus.

(3) - Instituto Nacional de Pesquisas da Amazônia, Manaus.

ACTA AMAZONICA 11(4): 729-741. 1981 
do Departamento de Entomologia do INPA, Dr. Warwick Kerr e Dr. João Camargo, da Faculdade de Medicina de Ribeirão Preto.

No período de frutificação, as contagens dos trutos foram feitas nos mesmos galhos em que foram contadas as inflorescências e flores. Tanto os frutos imaturos quanto os maduros que permaneciam nos galhos ou caídos embaixo de cada árvore foram contados com a finalidade de calcular-se a média dos frutos perdidos $\epsilon$ da safra da espécie. Foram pesados 500 frutos, ou seja, 50 frutos de cada árvore.

Dos frutos submetidos à pesagem, foram retiradas as sementes, polpas e cascas, as quais foram pesadas individualmente sendo que as sementes também foram contadas.

Foram feitas medidas do fuste, do diâmetro (DAP) e da copa das árvores em estudo, a fim de fazer-se uma correlação entre a idade e a produtividade dessas árvores.

Todos os resultados obtidos foram submetidos a diversos cálculos estatísticos como média aritmética, desvio padrão, erro-padrão da média, variância, coeficiente de variação, Teste " $t$ ", Teste d'Agostini, Curtose, regressäo linear, Teste $X^{2}$.

\section{CONSIDERAÇões gerais}

A sorva, Couma utilis, tem sido estudada em diversos aspectos por vários autores, dentre os quais se podem citar Cuervo (1894) que informou que o látex era usado pelos índios Ceona de Caquetá e do Putumayo (rio lça): Correa (1926) que estudou sua procedência, fitogeografia e valor industrial do látex; Huber (1904) e Ducke (1946) que consideraram a espécie como única do gênero cultivada nas cercanias de Manaus, sendo as outras silvestres. Hoehne (1946) a inclui entre as frutas indígenas, descrevendo e ressaltando seu valor econômico e medicinal; Ducke (1946) a colocoli entre as plantas de cultura pré-colombiana, considerando-o como árvore frutífera cultivada pelos índios da Amazônia e Fonseca (1954) em seu trabalho sobre "Frutas do Brasil", menciona a sorva, ressaltando o emprego alimentício do látex. Fróes (1959) e Heinsdijh e Bastos (1963) anotam sua presença na compo- sição florística da Hiléia amazônica; Patiño (1963) fez referência aos nomes vulgares e aspectos fitogeográficos; Albuquerque (1973) estudou a anatomia das folhas dando ênfase à distribuição geográfica. Prance \& Silva (1975). e Cavalcante (1976) fizeram referências mais pormenorizadas sobre aspectos botânicos, fenológicos, fitogeográficos e usos.

\section{a) ASPECTOS BOTÂNICOS}

Nome científico: Couma utilis Muell. Arg.

(Fig. 1)

Sinonimia: Collophora utilis Mart (1830) e Couma dulcis Spruce ex M.Arg. (1860).

Nomes vulgares: Brasil - sorva, cumã, cumai, couman, sorvinha, sorva-pequena.

\section{Familia: Apocynaceae}

Árvore de 2 a $12 \mathrm{~m}$ de altura. Folhas sim. ples, opostas e verticiladas, lâmina oblongoovada, estípulas presentes, membranáceas, in seridas nas axilas das folhas; inflorescências corimbas; de flores hermafroditas, actinomorfas, diclamideas, gamopétaias, receptáculos pequenos com pêlos esparsos; cálice com 5 sépalas, soldadas, pétalas 5 , contortas, soldadas da parte mediana para a base, rósea na base, clareando para o ápice na face externa, face interna rósea com partes esbranquiçadas; margem inteira; estames 4-5, inseridos nas paredes das pétalas, filete amarelo, anteras rimosas, dorsifixas, carpelo 1; ovário súpero, unilocular, pluriovular; óvulos anátropos, placentação parietal, 1, terminal, sagitado; estigma cilíndrico de dois lóbulos profundos. Fruto, baga, globoso látescente quando maduro; mesocarpo carnoso, comestível, com várias sementes.

\section{b) DISTRIBUIÇÃo GEOGRÁFICA E HABITAT}

Encontra-se uniformemente distribuída na parte central da Amazônia. No Estado do Amazonas, ocorre nos arredores de Manaus e principalmente no alto rio Negro; Cucuí; rio Solimões; Coari; Borba, Estrada Humaitá-Labrea e nos rios Purus, Japurá e Iça. No Estado do Pará, ocorre na missão Cururu (Alto Tapajós) 

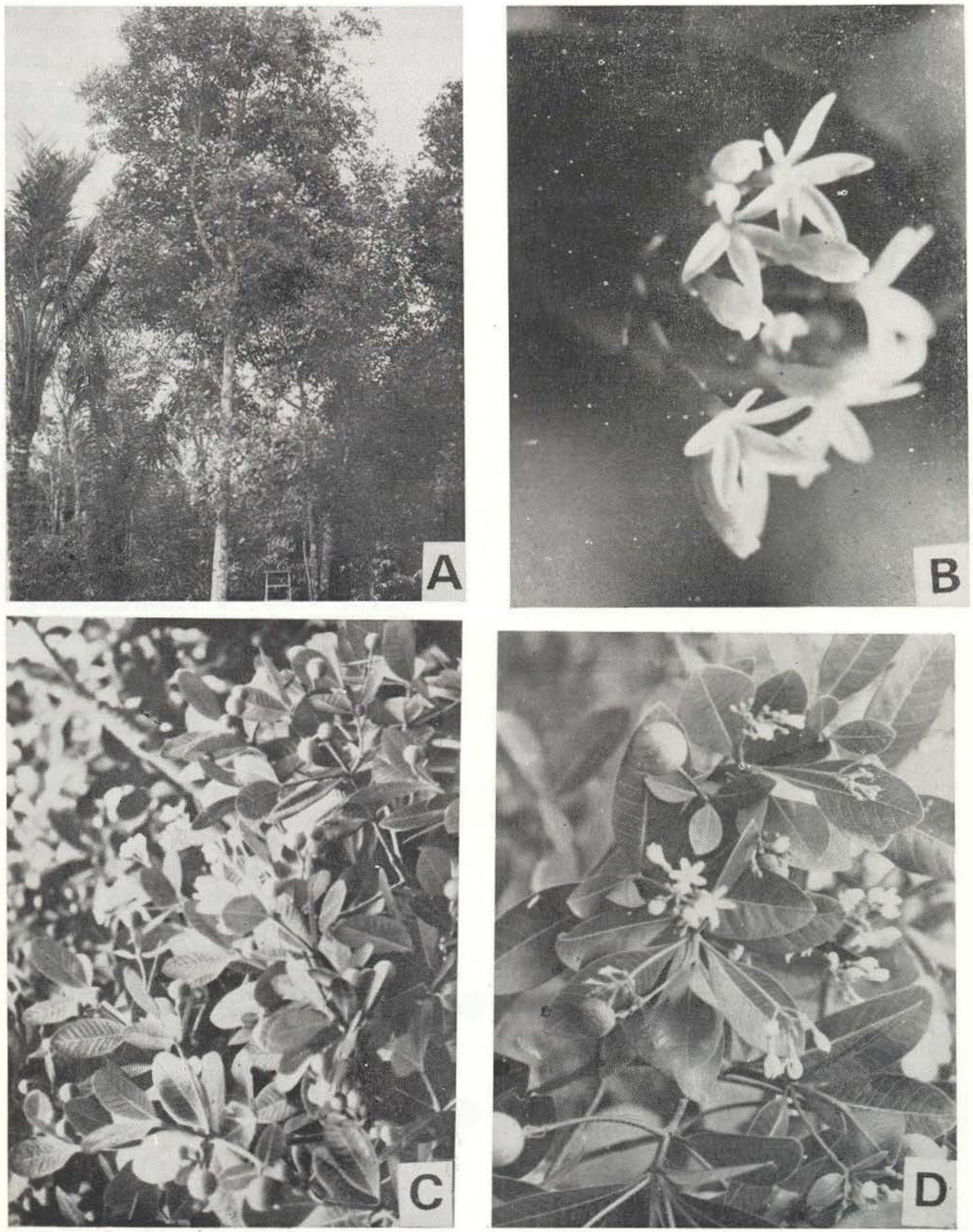

Fig. 1 - Couma utilis. a) - aspecto geral da árvore; b) —detalhe da flor; c) — detalhes da inflorescência; d) flores e frutos. 
e com mais freqüência nas cidades de óbidos e Faro. No Estado do Mato Grossc, é cultivada em Aripuanã. É também encontrada na Guiana (Caribe e Orinoco) e na Colômbia (Caquetá e Putumayo) (Porto, 1930; Le Cointe, 1947; Patiño, 1963; Albuquerque, 1973; Prance \& Silva, 1975; Cavalcante, 1976); Kerr et al., s.d.). (Fig. 2) .

Ocorre nas matas de terra firme, campos e campinas.

\section{c) USOS}

$\mathrm{O}_{3}$ frutos são comestiveis, apreciados pelos habitantes dá região e produzem um leite que, quando misturado com óleo de rícinio, é usado como anti-helmíntico no Norte (Hoehne, 1946). O látex, quando retirado da árvore, é potável, apresentando odor e sabor agradáveis, sendo empregado em mingaus (Fonseca, 1954) e quando retirado dos frutos solidifica em blocos compactos. É exportado em grande escala para a fabricação de goma de mascar. Quando adicionado a outras substâncias, apresenta emprego variável como calafetagem de canoas e, misturado com banana, é usado contra disen- teria pelos índios Ceona do Caquetá e Putumayo (Patiño, 1963). O látex puro produz borracha e é empregado na indústria de gomas e vernizes. Os frutos ainda produzem um suco que possui propriedades antivermifugas (Prance \& Silva, 1975). A goma combinada com tabatinga serve para caiação de casas (Cavalcante, 1976) .

\section{FENOLOGIA}

a) FLORAÇÃo

Nas árvores estudadas, a floração ocorreu entre 19 de abril e 3 de julho de 1977 e de 22 de fevereiro a 30 de junho de 1978 (Tabela 1). A abertura das flores realiza-se aproximadamente às 8 horas ou mais tarde dependendo da intensidade de iluminação, fechando-se ao anoitecer, entre 18 e 19 horas. A maioria das flores permanece fechada nos dias nublados ou chuvosus, e uma vez fecundadas perdem as pétalas.

Comparando-se o comportamento das árvores em estudos, nos dois anos de observação, notou-se que as árvores 8, 9 e 10 floresceram

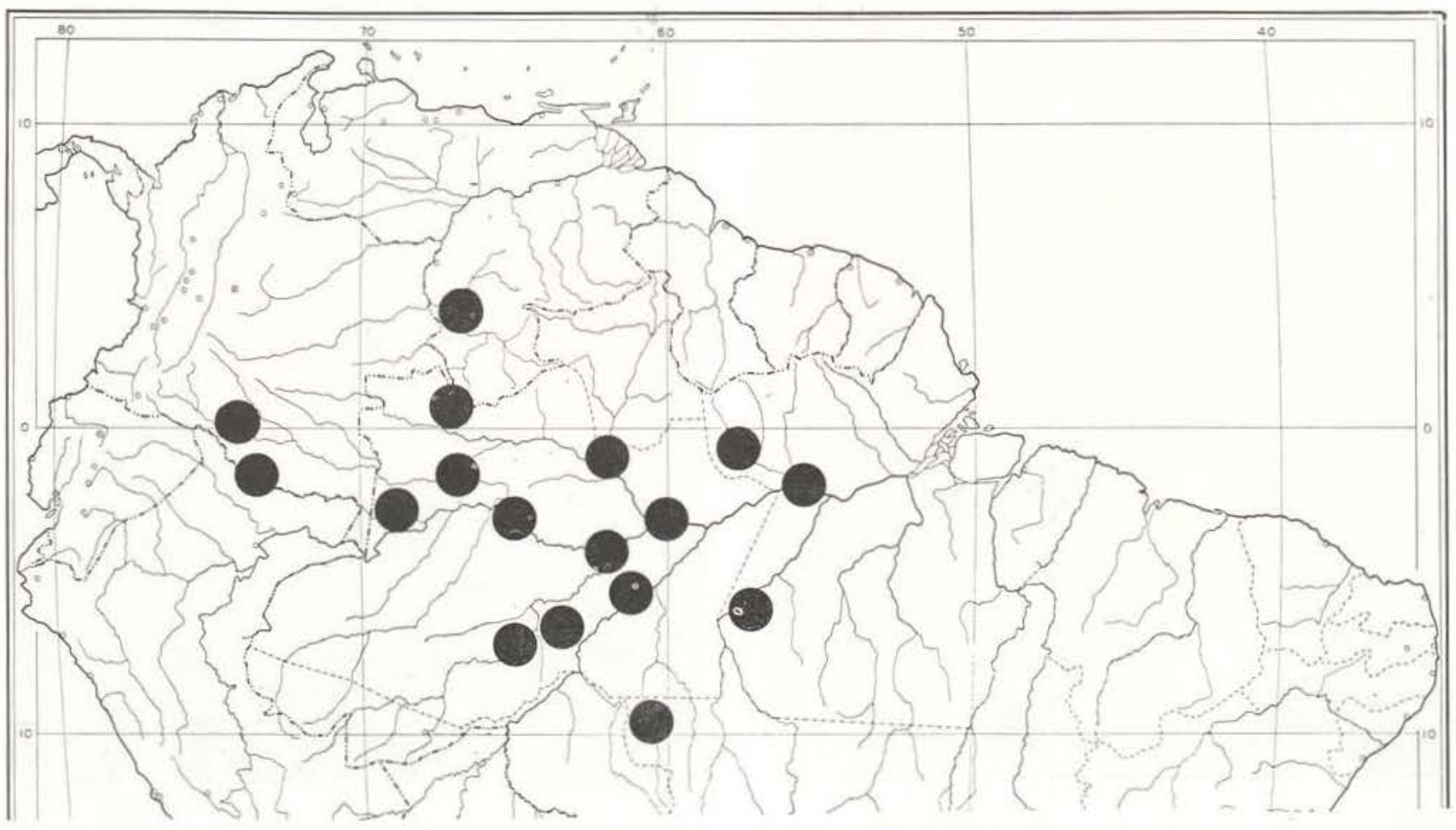

Fig. 2 - Distribuição geográfica conhecida de Couma utilis. 
TABELA 1 - Dados fenológicos básicos de Couma utilis, em 1977

\begin{tabular}{|c|c|c|c|c|c|c|c|c|c|c|}
\hline \multirow{3}{*}{ ESPECIFICAC̣ÃO } & \multicolumn{10}{|c|}{ DIAS - MESES } \\
\hline & \multicolumn{10}{|c|}{ ARVORES } \\
\hline & 01 & 02 & 03 & 04 & 05 & 06 & 07 & 08 & 09 & 10 \\
\hline INICIO DA FLORAÇÃO & 19.04 & 19.04 & 19.04 & 03.05 & 19.04 & 19.04 & 19.04 & 03.05 & 03.05 & 03.05 \\
\hline MAIOR FLORAÇÃO & 26.05 & 26.05 & 26.05 & 24.06 & 20.05 & 26.05 & 26.05 & 24.06 & 24.06 & 24.06 \\
\hline TÉRMINO DA FLORAÇĀO & 01.06 & 01.06 & 01.06 & 03.07 & 01.06 & 01.06 & 01.06 & 03.07 & 0307 & 03.07 \\
\hline PERIODO DA FLORAÇÃO & \multicolumn{3}{|c|}{19.04 a 01.06} & $\begin{array}{c}03.05 \\
a \\
03.07\end{array}$ & \multicolumn{3}{|c|}{19.04 a 01.06} & \multicolumn{3}{|c|}{03.05 a 03.07} \\
\hline INÍCIO DA FRUTIFICAÇĀO & 01.06 & 01.06 & 01.06 & 03.07 & 01.06 & 01.06 & 01.06 & 03.07 & 03.07 & 03.07 \\
\hline FRUTOS MADUROS (Safra) & 06.11 & 06.11 & 06.11 & 20.11 & 06.11 & 06.11 & 06.11 & 20.11 & 20.11 & 20.11 \\
\hline PERIODO DA FRUTIFICAÇÃO & \multicolumn{3}{|c|}{01.06 a 06.11} & $\begin{array}{c}03.07 \\
a \\
20.11\end{array}$ & \multicolumn{3}{|c|}{01.06 a 06.11} & \multicolumn{3}{|c|}{03.07 a 20.11} \\
\hline MUDANÇA FOLIAR & \multicolumn{3}{|c|}{05.01 a 14.02} & $\begin{array}{c}16.02 \\
a \\
16.02\end{array}$ & \multicolumn{3}{|c|}{ Q5.01 a 14.02} & \multicolumn{3}{|c|}{16.02 a 60.03} \\
\hline LOCALIZAÇÃO DAS ARVORES & \multicolumn{10}{|c|}{ ROSA DE MAIO } \\
\hline
\end{tabular}

mais ou menos na mesma época; no entanto o mesmo não aconteceu com as demais (Tab. 1 e 2; Fig. 3).

Uma análise de correlação entre os dados de floração, nos dois anos, mostrou que, em 1978, as árvores apresentaram uma tendência a florescer mais cedo que em $1977(r=0$, 631) com uma diferença significativa a nível de $5 \%$.

A figura 3 indica que a máxima floração em cada árvore ocorre 15 dias após o seu início.

Foi observado que o período médio entre o início de floração e frutificação, em 1977. foi de 39,5 dias $(\bar{x}=39,5 \pm 4,95)$ e em 1978, de 36 dias $(\bar{x}=36,0 \pm 13,22)$ (Tab. 3).

\section{b) FRUTIFICAÇÃo}

Em 1977, o período de frutificação de Couma utilis occrreu em 1 de junho e 6 de novembro (Tabela 1) com uma duração em mé- dia de 158 dias $(\bar{x}=158,0 \pm 12,72)$, como mostra a tabela 3. Em 1978, este período foi de 14 de março a 24 de agosto, com duração, de 164 dias (Tabela 2). A duração média de frutificação foi de 102,66 dias $(\bar{x}=102,66 \pm$ 32,50) (Tabela 3).

Em face de as 10 árvores estudadas estarem situadas na mesma área, no sítio Rosa de Maio, e apresentarem variações tanto no período de floraçãc quanto de frutificação pode supor-se que este fato esteja possivelmente correlacionado com fatores fisiológicos e genéticos. A coleta dos frutos é feita antes da completa maturação a fim de antecipar a sua comerciaiização. A maturação é feita colocando-se os frutos em caixotes com carbureto.

\section{c) MUDANÇA FOLIAR}

No ano de 1977. a mudança foliar ocorreu entre 5 de janeiro e 6 de março (Tab. 1), e, 
no ano de 1978 , esta mudança verificou-se $€$ tre 2 de janeiro e 1 de maio (Tab. 2) .

Ao analisar-se a ocorrência acima citada, notoui-se que as árvores 3, 5 e 1 apresentaram a mudança foliar na mesma época, nos dois anos de observação (Tab. 1 e 2).

\section{d) INSETOS VISITANTES}

Foram coletadas 14 espécies de insetos que visitavam freqüentemente as flores de Coume utilis. Dentre estas, 10 são abelhas e uma borboleta (Tabela 4) .
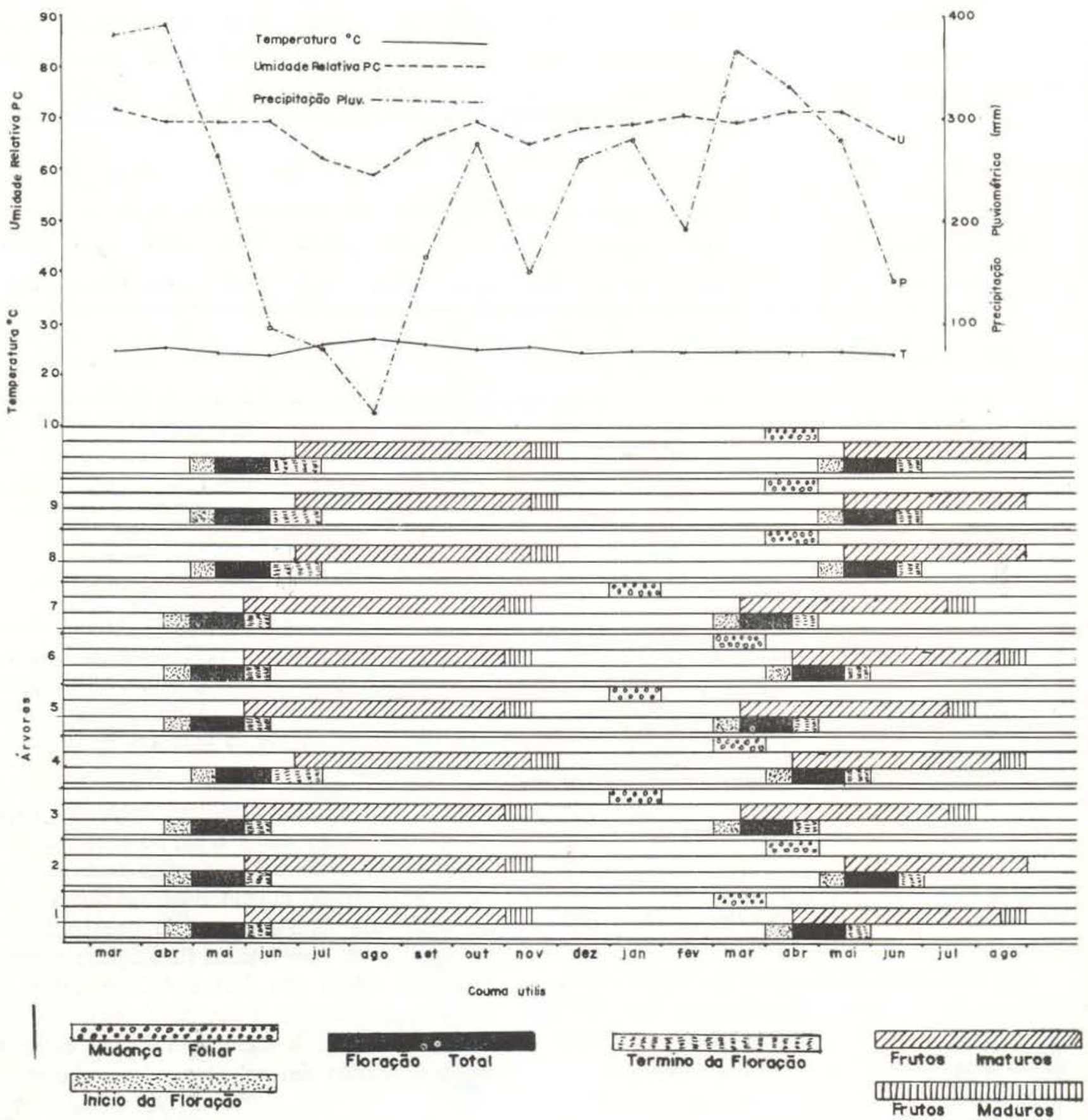

Fig. 3 - Couma utilis. Quadro geral de floração, frutificação produção e queda de folhas durante o período de março de 1977 a agosto de 1978. Acima, dados climatológicos para a área de Manaus, abaixo dados fenológicos. (Dados climatológicos de Ribeiro, 1977). 
TABELA 2 - Dados fenológicos básicos de Couma utilis, em 1978

\begin{tabular}{|c|c|c|c|c|c|c|c|c|c|c|}
\hline \multirow{3}{*}{ ESPECIFICAÇĀO } & \multicolumn{10}{|c|}{ DIAS - MESES } \\
\hline & \multicolumn{10}{|c|}{ ARVORES } \\
\hline & 01 & 02 & 03 & 04 & 05 & 06 & 07 & 08 & 09 & 10 \\
\hline INICIO DA FLORAÇĀO & 04.04 & 0205 & 22.02 & 04.04 & 22.02 & 04.04 & 22.02 & 02.05 & 02.05 & 02.05 \\
\hline MAIOR FLORAÇĀO & 15.05 & 13.06 & 16.03 & 15.05 & 16.03 & 15.05 & 16.03 & 13.06 & 13.06 & 13.06 \\
\hline TÉRMINO DA FLORAÇĀO & 28.05 & 30.06 & 23.04 & 28.05 & 23.04 & 28.05 & 23.04 & 37.06 & 3006 & 30.06 \\
\hline PERIODO DA FLORAÇÃO & $\begin{array}{c}04.04 \\
a \\
28,05\end{array}$ & $\begin{array}{c}02.05 \\
a \\
30.06\end{array}$ & $\begin{array}{c}22.02 \\
\text { a } \\
23.04\end{array}$ & $\begin{array}{c}04.04 \\
a \\
28.05\end{array}$ & $\begin{array}{c}22.02 \\
a \\
23.04\end{array}$ & $\begin{array}{c}04.04 \\
\text { a } \\
28.05\end{array}$ & $\begin{array}{c}22.02 \\
\text { a } \\
2304\end{array}$ & $\begin{array}{c}02.05 \\
\text { a } \\
3006\end{array}$ & $\begin{array}{c}02.05 \\
\text { a } \\
30.06\end{array}$ & $\begin{array}{c}0205 \\
0 \\
30.06\end{array}$ \\
\hline INICIO DA FRUTIFICAÇĀO & 14.05 & 16.06 & 14.03 & 14.05 & 14.03 & 14.05 & 14.03 & 16.06 & 16.06 & 16.06 \\
\hline FRUTOS MADUROS (Safra) & \multicolumn{2}{|c|}{24.08} & 26.07 & 24.08 & 26.07 & 24.08 & 26.07 & 24.08 & 24.08 & 24.08 \\
\hline PERIODO DA FRUTIFICAÇĀO & $\begin{array}{c}14.05 \\
a \\
24.08\end{array}$ & $\begin{array}{c}16.06 \\
a \\
24.08\end{array}$ & $\begin{array}{c}14.03 \\
a \\
26.07\end{array}$ & $\begin{array}{c}14.05 \\
a \\
24.08\end{array}$ & $\begin{array}{c}14.03 \\
a \\
26.07\end{array}$ & $\begin{array}{c}14.05 \\
a \\
24.08\end{array}$ & $\begin{array}{c}14.03 \\
a \\
26.07\end{array}$ & $\begin{array}{c}16.06 \\
a \\
24.08\end{array}$ & $\begin{array}{c}16.06 \\
a \\
24.08\end{array}$ & $\begin{array}{c}16.06 \\
a \\
24.08\end{array}$ \\
\hline MUDANÇA FOLIAR & $\begin{array}{c}03.03 \\
\text { a } \\
02.04\end{array}$ & $\begin{array}{c}04.04 \\
\text { a } \\
01.05\end{array}$ & $\begin{array}{c}02.01 \\
\text { a } \\
05.02\end{array}$ & $\begin{array}{c}03.03 \\
a \\
02.04\end{array}$ & $\begin{array}{c}02.01 \\
a \\
05.02\end{array}$ & $\begin{array}{c}03.03 \\
a \\
03.04\end{array}$ & $\begin{array}{c}02.01 \\
a \\
05.02\end{array}$ & $\begin{array}{c}04.04 \\
a \\
01.05\end{array}$ & $\begin{array}{c}04.04 \\
a \\
01.05\end{array}$ & $\begin{array}{c}04.04 \\
\text { a } \\
01.05\end{array}$ \\
\hline LOCALIZAÇĀO DAS ÁRVORES & \multicolumn{10}{|c|}{ ROSA DE MAIO } \\
\hline
\end{tabular}

TABELA 3 - Duração em dias dos principais eventos durante a frutificação de Couma utilis

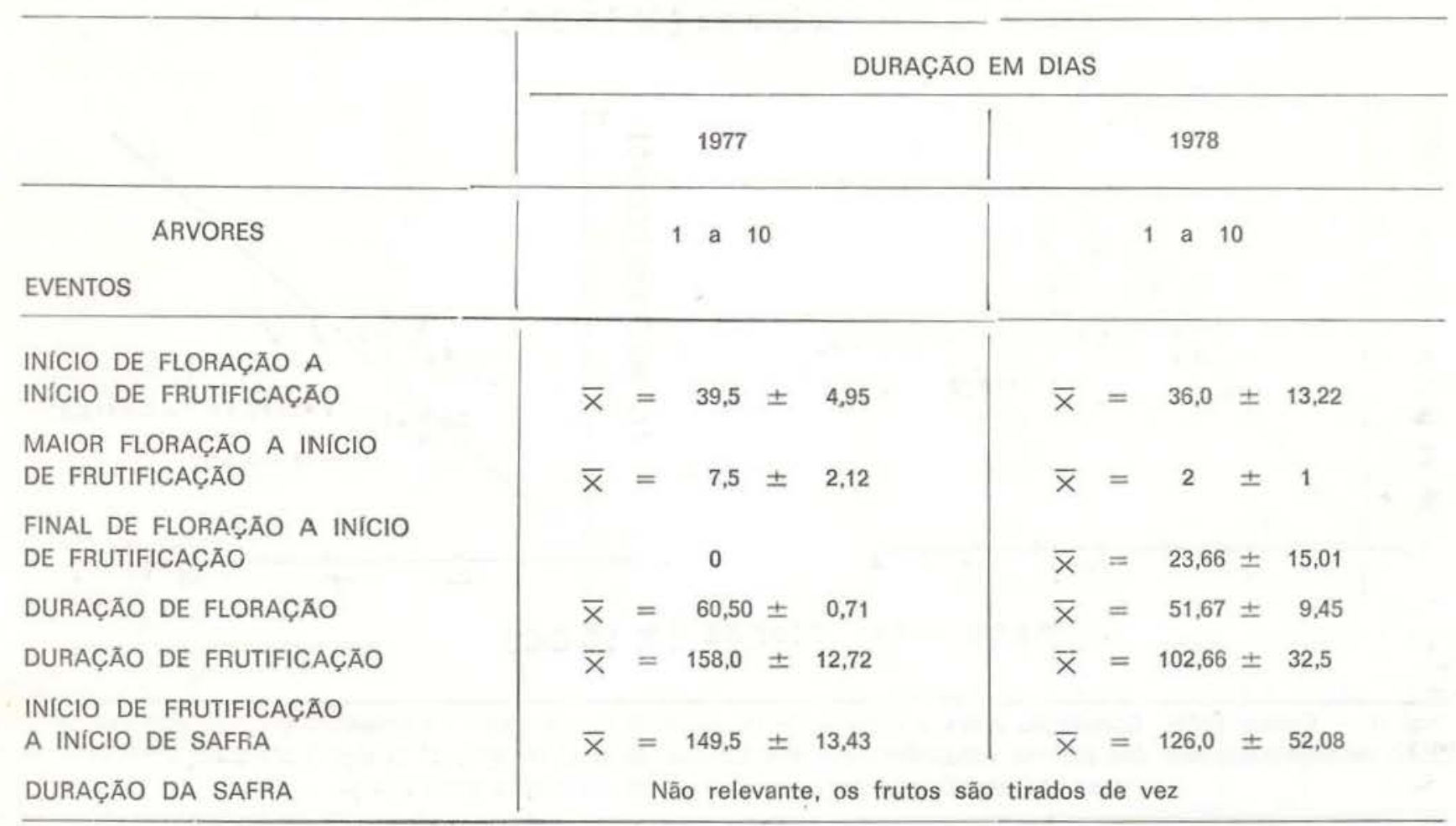


As espécies encontradas polinizando as flores foram as abelhas Eulaema (Apeulaema) mocseryi Friese, Epicharis sp. e Xylocopa (Megaxylocopa) frontalis Lep.. A seguir, verificaram-se outras duas espécies (Eulaema nigrita Lep,. Tetrapedia sp.) e uma borboleta (Dione juno juno (Cr.) Heliconidae). As demais es. pécies foram esporádicas, não sendo identificadas. O mais interessante foi não terem sido encontrados meliponideos, que, segundo Kerr (Comum. Pessoal), são grandes polinizadores de plantas da Amazônia. Absy \& Kerr (1977) indicaram várias plantas visitadas para obtenção de pólen por operárias de Melipona em Manaus.

As flores de Couma utilis precisam de um agente polinizador para serem fecundadas, pois, quando revestidas com envoltórios d? filó, não apresentaram nenhum vestígio de fecundação. Foi feito um teste $X^{2}$ que deu uma probabilidade de $99,9 \%$ de que as flores de Couma utilis são polinizadas por insetos.

Quanto ao número de grãos de pólen elrcontrados nas patas de insetos visitantes, ve-
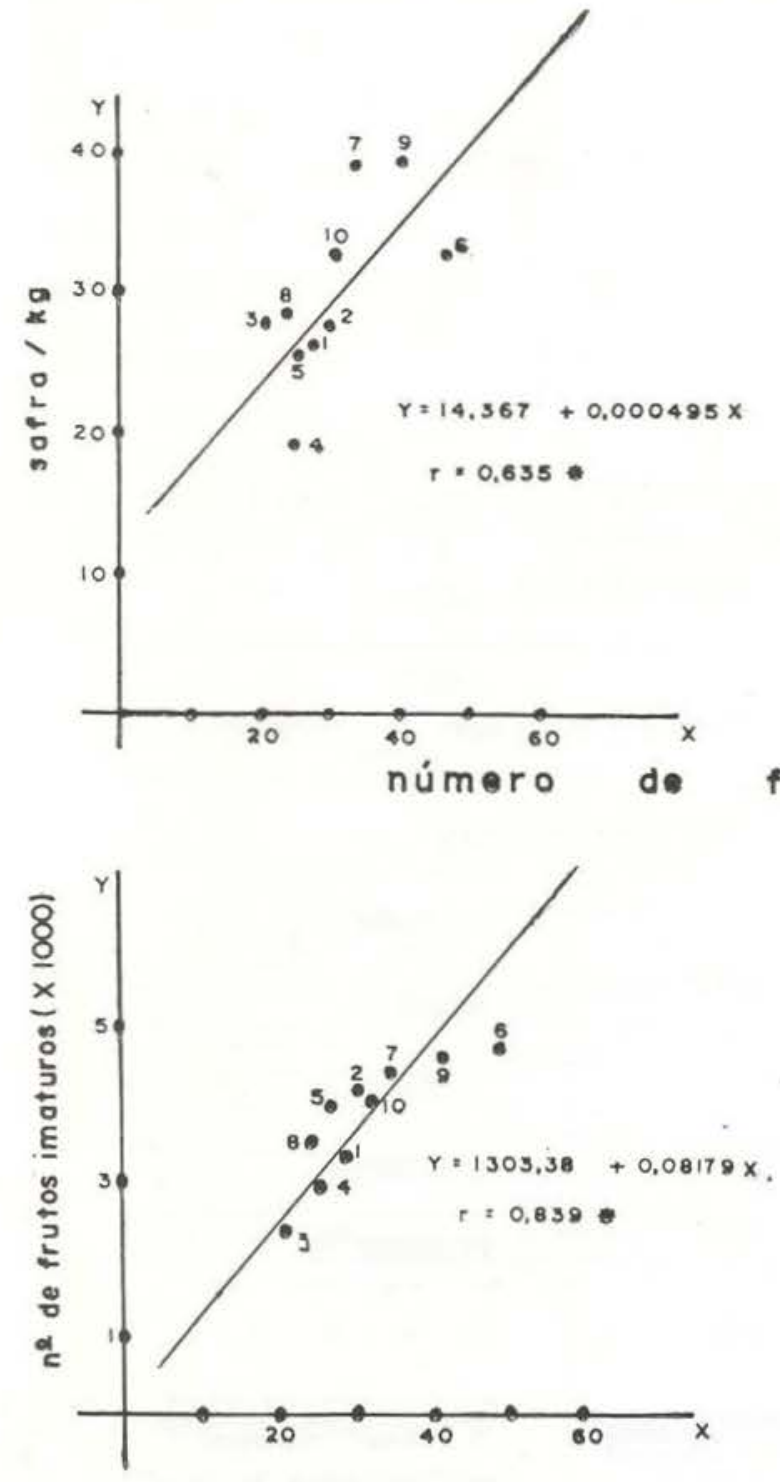
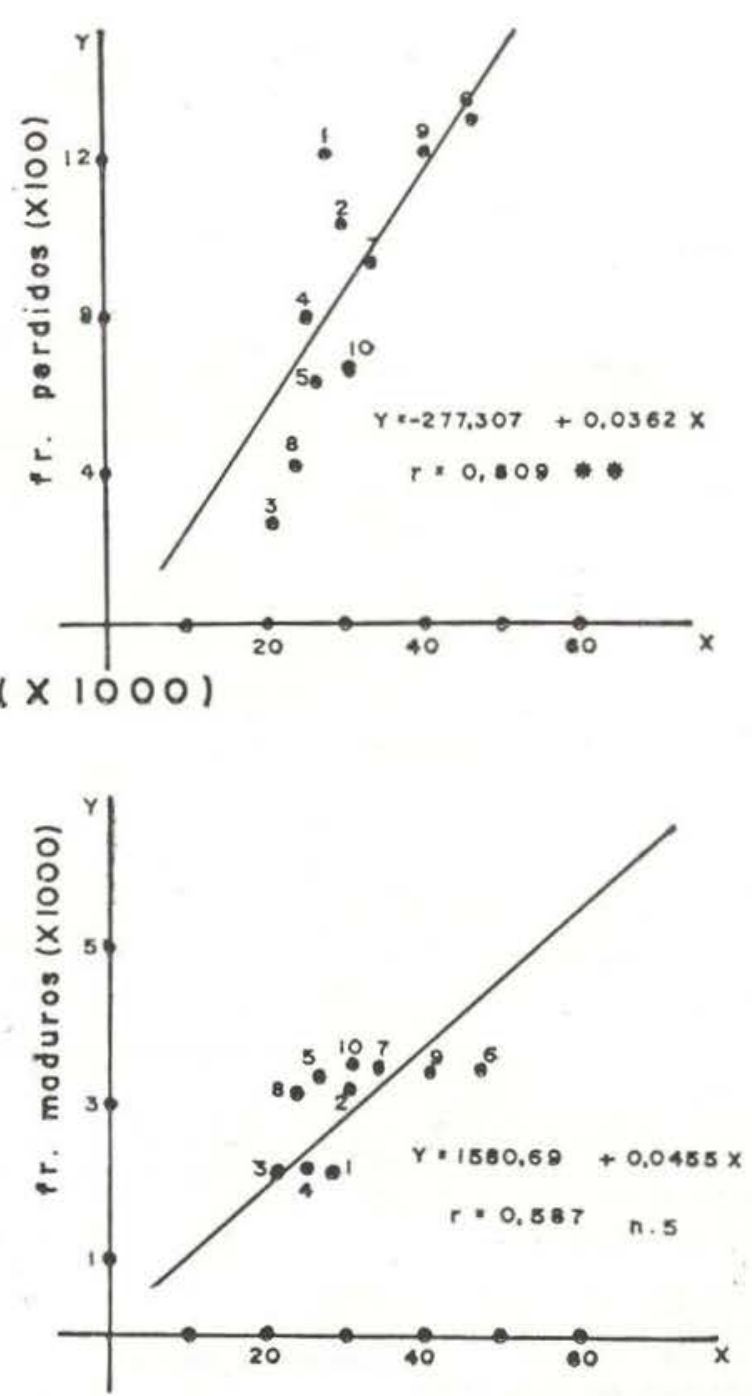

número

de flores $(\times 1000)$

Fig. 4 - Couma utilis. Correlação entre o número de flores $(x)$ e outros dados de produção (y). Os números de 1 a 10 correspondem aos das árvores estudadas. $\left({ }^{\circ}\right)$, significativa ao nível de $5 \%$; $\left({ }^{* *}\right)$, significativa ao nível de $1 \%$; n.s., năo significativo; $r=$ coeficiente de correlaçăo entre $x$ e $y$. 
rificou-se que nas lâminas de Eulaema (Apeulaema) moscaryi Friese, Spicharis sp. e Xylocopa (Megaxylocopa) frontalis foram encontrados entre 500 a 1000 grãos, todos de Couma utilis e, em Dione juno juno, Eulaema nigrita e Tetrapedia sp., este número foi inferior a 500 grãos, sendo não só de Couma utilis mas também misturadas com os de outras espécies.

TABELA 4 - Espécies de insetos encontrados em Couma utilis, Quantidades de pólen encontrados nas patas dos mesmos

\begin{tabular}{|c|c|c|c|c|}
\hline Ordem & Familia & Espécie & $\begin{array}{c}\text { Grão de pólen } \\
\text { por amostra }\end{array}$ & Col./N. Coleta \\
\hline $\begin{array}{l}\text { Hymenoptera } \\
\text { Hymenoptera } \\
\text { Hymenoptera } \\
\text { Hymenoptera } \\
\text { Hymenoptera } \\
\text { Hymenoptera } \\
\text { Hymenoptera } \\
\text { Hymenoptera } \\
\text { Hymenoptera } \\
\text { Hymenoptera } \\
\text { Lepidoptera }\end{array}$ & $\begin{array}{l}\text { Apidae } \\
\text { Apidae } \\
\text { Apidae } \\
\text { Apidae } \\
\text { Apidae } \\
\text { Apidae } \\
\text { Apidae } \\
\text { Apidae } \\
\text { Apidae } \\
\text { Apidae } \\
\text { Heliconiidae }\end{array}$ & $\begin{array}{l}\text { Eulaema (Apeulaema) mocsaryi Friese } \\
\text { Eulaema nigrita Lepetier } \\
\text { Epicharis sp. } \\
\text { Tetrapedia sp. } \\
\text { Xylocopa (Megaxylocopa) frontalis (Olivier) } \\
\text { Não identificada } \\
\text { Não identificada } \\
\text { Não identificada } \\
\text { Não identificada } \\
\text { Não identificada } \\
\text { Dione juno juno }(\mathrm{Cr} \text {.) }\end{array}$ & $\begin{array}{c}640 \\
370 \\
730 \\
480 \\
930 \\
0 \\
0 \\
0 \\
0 \\
0 \\
263\end{array}$ & $\begin{array}{lr}\text { M. Falcão, } 28 \\
\text { M. Falcão, } 50 \\
\text { M. Falcão, } 48 \\
\text { M. Falcão, } 12 \\
\text { M. Falcão, } 3 \\
\text { M. Falcão, } 49 \\
\text { M. Falcão, } 55 \\
\text { M. Falcão, } 56 \\
\text { M. Falcão, } 57 \\
\text { M. Falcão, } 58 \\
\text { M. Falcão, } 59\end{array}$ \\
\hline
\end{tabular}

TABELA 5 - Couma utilis. Média dos dados básicos de produção, incluindo entre outros flores, frutos maduros e imaturos e peso da safra das árvores em estudo, entre abril de 1977 e agosto de 1978

\begin{tabular}{|c|c|c|c|c|c|c|c|c|c|c|c|c|c|c|c|c|}
\hline & & & & & & $\mathrm{N}$ & M & $E$ & $\mathrm{R}$ & & & & & & & \\
\hline \multirow{5}{*}{ 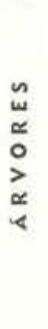 } & \multicolumn{3}{|c|}{$G A L H O S$} & \multicolumn{3}{|c|}{ FLORES } & \multicolumn{7}{|c|}{$\begin{array}{lllllll} & R & \mathbf{R} & \mathbf{T} & \circ & \mathbf{S}\end{array}$} & \multirow{2}{*}{\multicolumn{3}{|c|}{ SE MENTES }} \\
\hline & \multirow{4}{*}{ Árvore } & \multicolumn{2}{|c|}{ INFL. } & INFL. & & $\%$ & IMAT & UROS & & $M A$ & D U & $R \circ S$ & & & & \\
\hline & & \multirow{3}{*}{$\bar{x}$} & \multirow{3}{*}{ EP } & \multirow{3}{*}{$\bar{x}$} & \multirow{3}{*}{ TOTAL } & \multirow{3}{*}{$\begin{array}{l}\text { Fruti. } \\
\text { fica- } \\
\text { çẫo }\end{array}$} & \multirow{3}{*}{$\begin{array}{l}\text { Por } \\
\text { galho } \\
\bar{\nabla}\end{array}$} & \multirow{3}{*}{$\begin{array}{l}\text { Estim. } \\
\text { na } \\
\text { árrore }\end{array}$} & \multirow{3}{*}{ TOTAL } & \multicolumn{3}{|c|}{$P$ E S S O } & \multirow{3}{*}{$\begin{array}{l}\text { ESTIM. } \\
\text { PERD. }\end{array}$} & $\mathbf{P}$ & E $S$ & 0 \\
\hline & & & & & & & & & & \multicolumn{2}{|c|}{ GRAMAS } & \multirow{2}{*}{$\frac{\text { ESTIM. }}{\text { KG. }}$} & & \multicolumn{2}{|c|}{ GRAMAS } & \multirow{2}{*}{$\begin{array}{l}\text { ESTIM. } \\
\text { KG. }\end{array}$} \\
\hline & & & & & & & & & & $\bar{x}$ & EP & & & $\bar{x}$ & EP & \\
\hline 01 & 20 & 81,67 & 10,49 & 17,49 & 28.561 & 11,59 & 167 & 3.340 & $2.12 \mathrm{U}$ & 12,36 & 0,75 & 26,203 & 1.220 & 0,33 & 0,02 & 0,699 \\
\hline 02 & 18 & 142,33 & 29,45 & 12,59 & 32.254 & 13,11 & 235 & 4230 & 3.195 & 8,56 & 0,49 & 27,349 & 1.035 & 0,27 & 0,01 & 0,862 \\
\hline 33 & 18 & 64,33 & 8,59 & 18,17 & 21.039 & 11,21 & 131 & 2.358 & 2.687 & 12,98 & 0,82 & 27,089 & 271 & 0.29 & 0,01 & 0,605 \\
\hline 04 & 21 & 63,00 & 8,51 & 19,49 & 25.785 & 11,48 & 141 & 2.961 & 2.150 & 8,97 & 0,58 & 19,285 & 811 & 0,30 & 0,01 & 0,645 \\
\hline 05 & 18 & 151,67 & 10,28 & 9,77 & 26.672 & 15,05 & 223 & 4.014 & 3.380 & 7,64 & 0,49 & 25,823 & 634 & 0,38 & 0,02 & 1,284 \\
\hline 06 & 30 & 139,33 & 12,85 & 11,31 & 47.274 & 10,09 & 159 & 4.770 & 3.470 & 9,45 & 0,67 & 32,791 & 1.300 & 0,34 & 0,01 & 1,179 \\
\hline 07 & 26 & 79,33 & 13,40 & 16,36 & 33.743 & 13,10 & 170 & 4.420 & 3.496 & 11,16 & 0,58 & 39,015 & 924 & $\mathrm{e}, 34$ & 0,16 & 1,188 \\
\hline 08 & 22 & 77,00 & 10,08 & 14,20 & 24.054 & 14,91 & 163 & 3.586 & 3.176 & 8,90 & 0,61 & 28,266 & 410 & 0,32 & 0,01 & 1,016 \\
\hline 09 & 29 & 125,67 & 0,88 & 11,21 & 40.854 & 11,36 & 160 & 4.640 & 3.400 & 11,55 & 0,63 & 39,270 & 1.240 & 0,31 & 0,02 & 1,054 \\
\hline 10 & 23 & 117,00 & 11,80 & 11,49 & 30.919 & 13,46 & 181 & 4.163 & 3.500 & 9,33 & 0,45 & 32,655 & 663 & 0,30 & 0,10 & 1,050 \\
\hline
\end{tabular}


TABELA 6 - Medidas de diâmetro (DAP), altura do fuste, altura total e a idade das árvores estudadas de Couma utilis

\begin{tabular}{|c|c|c|c|c|c|}
\hline Local & Arvores & $\begin{array}{l}\text { Diâmetro (DAP) } \\
(\mathrm{cm})\end{array}$ & $\begin{array}{l}\text { Altura do Fuste } \\
\qquad(\mathrm{m})\end{array}$ & Altura Total & $\begin{array}{l}\text { Idade } \\
\text { (anos) }\end{array}$ \\
\hline \multirow{10}{*}{ ROSA DE MAIO } & 1 & 23,89 & 2,50 & 7,50 & 15 \\
\hline & 2 & 23,56 & 2,00 & 7,00 & 15 \\
\hline & 3 & 20,06 & 2,20 & 7,20 & 15 \\
\hline & 4 & 11,94 & 4,00 & 10,00 & 15 \\
\hline & 5 & 23,88 & 2,00 & 7,00 & 15 \\
\hline & 6 & 17,20 & 2,00 & 8,00 & 15 \\
\hline & 7 & 29,30 & 2,00 & 8,00 & 15 \\
\hline & 8 & 14,02 & 2,20 & 7,70 & 15 \\
\hline & 9 & 28,02 & 2,90 & 9,90 & 15 \\
\hline & 10 & 19,42 & 3,20 & 10,20 & 15 \\
\hline
\end{tabular}

Além desses, foram observados outros insetos visitantes, os quais não puderam ser, até o momento, identificados, e que transportavam pólen.

\section{ANÁLISE DE PRODUÇão}

Na tabela 5 , encontram-se as médias dos dados básicos de produção de flores, frutos imaturos e maduros, peso da safra e das se. mentes, percentagens de flores que frutificaram e frutos perdidos entre abril de 1977 a agosto de 1978.

A produção média do peso dos frutos maduros de Couma utilis foi $\bar{x}=29,775 \pm 6,21$ $\mathrm{kg}$. A média estimada de flores é 31.116 por árvore, produzindo uma média de 2.997 frutos, ou seja, $12,5 \%$.

A correlação entre o número de flores e o peso de frutos maduros (safra) foi significativa ao nível de $5 \%\left(r=0,635^{*}\right)$. Entretanto, as correlações entre número de flores e frutos perdicios $\left(r=809^{* *}\right)$ e o número de flores e frutos imaturos $\left(r=0,839^{* *}\right)$ foram significativas ao nivel de $1 \%$. Quanto à correlação entre o número de flores e frutos maduros $(r=0,587)$, não houve diferença significativa (Fig. 4) .

Como as correlações entre o peso dos frutos e o diâmetro (DAP) altura do fuste, altura da copa, altura total e a idade das árvores em estudo, não foram significantes, deixou-se de apresentar os gráficos correspondentes. A tí- tulo de ilustração a tabela no 6 contém os dados utilizados.

O valor de correlação entre o número de frutos imaturos e o número de frutos maduros $\left(r=0,893^{* *}\right)$ foi significativo ao nível de $1 \%$ (Fig. 5) .

Analisando os dados referentes aos pesos do fruto total, da polpa e da semente (Fig. 6). verificou-se claramente, que há uma correlação entre o peso do fruto e u da polpa, ou seja quanto maior é o fruto, maior é a polpa. Isso,

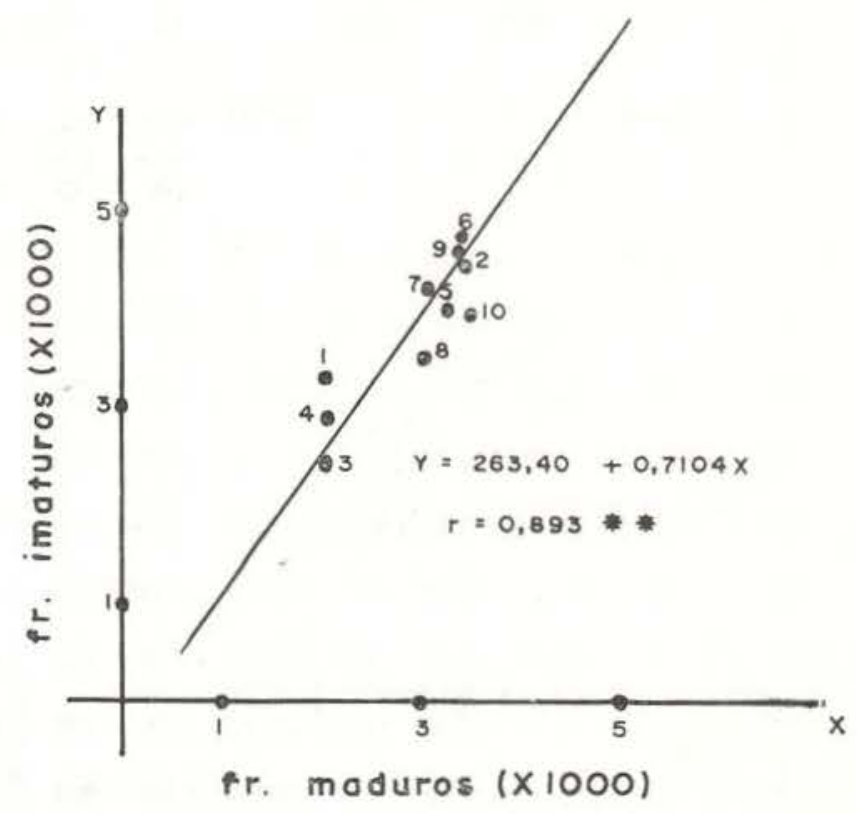

Fig. 5-Couma utilis. Regressāo linear comparando o número de frutos maduros $(x)$ e número de frutos imaturos $(\mathrm{y}) .\left({ }^{* *}\right)$ significativo ao nível de $1 \%$. 
no entanto, não é acompanhado pelo peso da semente. É possivel que isto se deva ao número de sementes sendo que, muitas vezes, nem todos os óvulos são fecundados ou desenvolvidos.

Do ponto de vista evolutivo, é de grande interesse o fato de a variância das sementes ser menor que a do peso dos frutos e da polpa indicando que, quer o fruto seja grande quer pequeno, as sementes tendem a ter um mesmo número e peso.

É possivel que a evidente bimodalidade das curvas dos pesos dos frutos (e polpa) se deva a um, dois ou três surtos de flores abertas ou de polinizadores; mais pesquisa é necessária neste campo.

Utilizando os 20 primeiros dados nos quais foi baseada a figura 6 , foi feita a correlação entre o peso do fruto e peso da polpa. A correlaçäo foi altíssima ( $r$ 0,9995; $\propto=0,417$; $\beta=0,998$ ) como era de esperar-se por mera observação dos gráficos; os mesmos 20 primeiros dados de peso dos frutos foram comparados com pesos das sementes com correlação ( $r=0,051)$ não significativa.

Em termos gerais, os dados aqui apresentados para a sorva são bem semelhantes aos encontrados nas duas espécies discutidas anteriormente (Umari e Mapati). Ainda se as correlações entre número de flores e outros parâmetros de produção não são tão altas quanto no Umari e Mapati, continuam sendo estatística e biologicamente significativas.

Assim a correlação entre número de flores e frutos imaturos $(r=0,839)$ é significativa ao nivel de $1 \%$, assim como a correlação entre número de flores e número de frutos perdicios. Como nas espécies discutidas anteriormente, isto sugere que a perda de frutos não é fortuita.

O fato de os frutos serem tirados das árvores antes de amadurecer totalmente, pode em parte, ser a causa da baixa correlação entre números de flores e número de frutos maduros $(r=0,587)$; há certamente um processo de "seleção" pelo fruticultor que despreza alguns frutos em virtude de estes não terem atingido tamanho ou nível de maturação comercial. De fato, os frutos aqui chamados de "maduros" poderiam ser melhor chamados de "aptos a

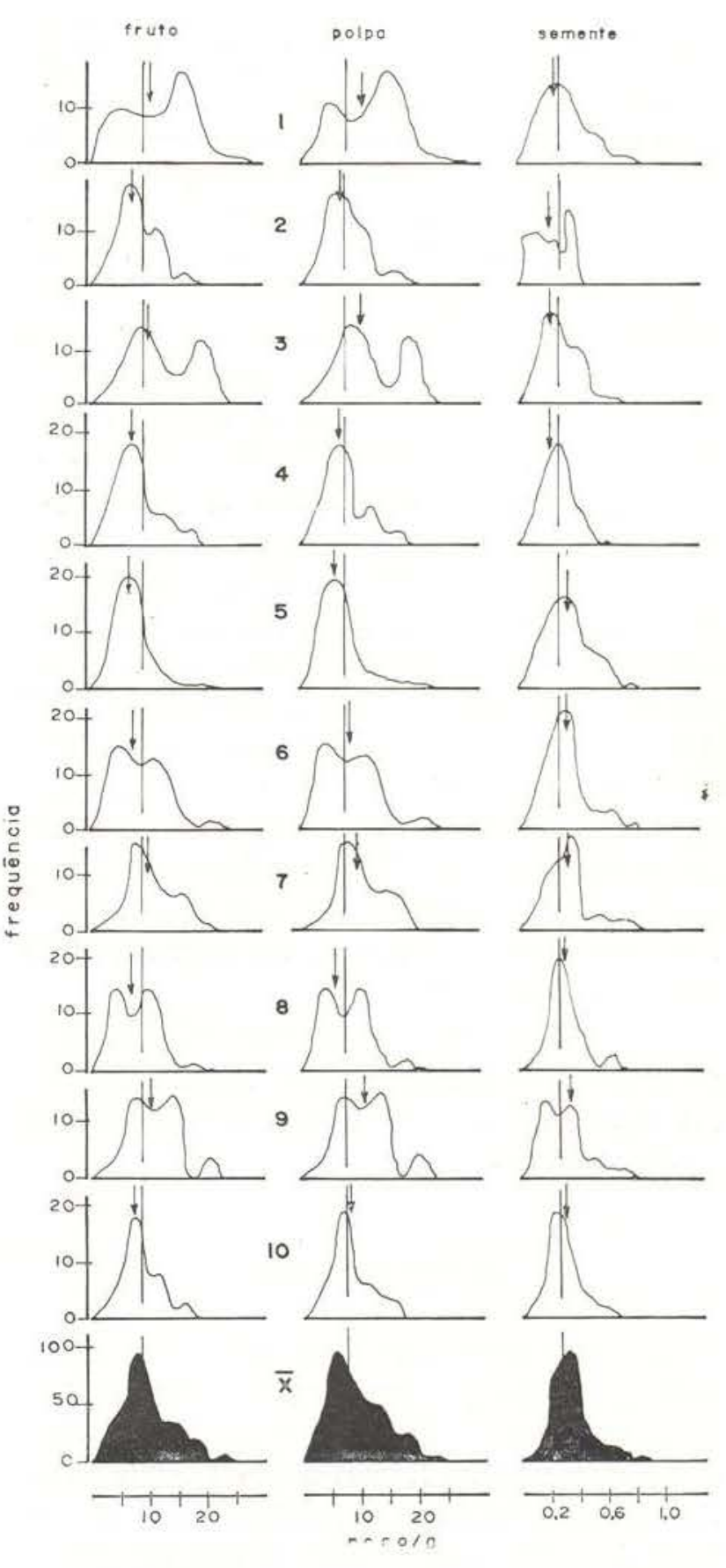

Fig. 6 - Couma utilis. Freqüências de pesos de fruto total, polpa e sementes das 10 árvores, e, das suas médias. A linha que atravessa os gráficos representa a média das médias; a seta em cada gráfico representa a sua média.

serem retirados para serem vendidos", sendo que nenhum deles está realmente maduro. Em alguns experimentos de germinação, verificamos que de 100 sementes tiradas de frutos "amadurecidos" com carbureto, só 2 germina- 
ram; de 100 sementes tiradas de frutos deixados amadurecer nas árvores, 94 germinaram.

Ainda que a correlação entre número de flores e frutos "maduros" não seja significativa, foi significativa a nívei de $5 \%(r=0,635)$ entre o número de flores e peso da safra. Então, ainda descontando o erro metodológico induzido pela colheita da safra de vez como já foi discutido, fica evidente que o número de flores é uma expressão do peso da safra, como nas duas espécies anteriormente descritas.

A sorva apresenta índices de polinização relativamente baixos (aprox. 12\%), sendo mais semelhantes ao Umari do que ao Mapati; como nos casos anteriores, não se pode considerar um únicc polinizador e sim um síndrome de polinização, com polinizadores bem distintos das dias espécies já mencionadas.

Também é notória a semelhança da sorva com o Umari e Mapati, quanto a alta correlação entre número de flores e número de frutos perdidos $(r=0,809)$, (significativa a $1 \%$ ). Mais uma vez, isto sugere um controle endógeno de safra.

A discussão dos aspectos fisiológicos aqui descritos pode ser consultada no trabalho dos presentes autores sobre o Umari (Falcão \& Lleras, 1980 a) .

\section{AgRAdECIMENTOS}

Agradecemos de maneira muito especial a revisão crítica do manuscrito, sugestões e apoio a Warwick Estevam Kerr, Maria Lúcia Absy, Herbert Otto Rogert Shubart, Angela Maria Cunte Leite, Lea Maria Medeiros Carreira, Hugo Menezes dos Santos e sua equipe de precessamento de dados, assim como a todas outras pessoas que colaboraram direta $e$ indiretamente. No trabalho de campo somos gratos a Osmarino Pires Monteiro pela sua eficiente colaboração.

\section{SUMMARY}

Data or phenology, ecology and productivity of "sorva" (Couma utilis Muell Arg.) are here presented. In Manaus, the species flowers and sets fruit during the height of the rainy season with the crop during the dry season. Eleven species of insects were found visiting the species of which ten were Apiidae and one Heliconiidae. It is postulated that there is no pollination specificity. The number of flowers produced varied between 21.000 and 47.000 in the ten trees studied with fruit set or between 10 and $15 \%$. Very high correlations were found between number of flowers and other production parameters such as green fruit, mature fruit and crop weight suggesting that factors other than pollination may play important roles in determining crop size.

\section{REFERENCIAS BIBLIOGRAFICAS}

ABSY, M.L. \& KERR, W.E.

1977 - Algumas plantas visitadas para obtençăo de pólen por operárias de Melipona seminigra merrillae em Manaus. Acta Amazonica, 7 (3): $309-315$.

ALBUQUERQUE, B.W.P.

1973 - Contribuição ao conhecimento de Couma macrocarpa Barb, Rodr. e Couma utilis (Mart.) M. Arg. (Apocynaceae) da Amazônia. Acta Amazonica, 3 (2): 7-15.

CAVALCANTE, P.B.

1976 - Frutas Comestiveis da Amazônia. 3 ed. Belém, INPA. 166p.

CORREA, M.P.

1926 - Dicionário das Plantas úteis do Brasil e das Plantas Exóticas Cultivadas. Rio de Janeiro, Serviço de Inf. Agrícola. Vol. 6, 143p.

CUERVO, A.B.

1894 - I. IV Sección 2.: Geografia - Viagens Missiones - Limites. Casanare $\mathrm{Y}$ el $\mathrm{Ca}$. quetá durante 10 Colonia. Bogotá, 516p. (Apud Patiño, 1963).

DUCKE, A.

1946 - Plantas de Cultura pré-colombiana na Amazônia brasileíra. Bol. Téc. Inst. Agron. Norte, Belém, (8): 1 a $14 p$.

ERDTMAN, G.

1960 - The acetolysis method: - a revised description. Sv. Bot. Tidskr. Lund., 54 (3): 561 564.

FALCÃO, M.A. \& LLERAS, E.

1980a- Aspectos Fenológicos, Ecológicos e de Produtividade do Umari (Poraqueiba sericea) Tulasne. Acta Amazonica, 10 (3): 445-462.

1980b- Aspectos Fenológicos, Ecológicos e de Produtividade do Mapati (Pourouma cecropiifolia). Acta Amazonica, 10 (4): 711-724.

FONSECA, E.T.

1954 - Frutas do Brasil. Rio de Janeiro, Inst. Nac. Livro, 281p.

FROES, R.L.

1959 - Informaçōes sobre algumas plantas do Planalto Amazônico. Bol. Téc. Inst. Agron. Norte, Belém, 35: 3-113 (Apud. Cavalcante, 1976). 
HEINSDIJH, D.; BASTOS, A. de M.

1963 - Inventários florestais na Amazônia. Bol. Ser. Flor., Rio de Janeiro 6: 1-100, ilust. (Apud Albuquerque, 1973).

HOEHNE, F.C.

1946 - Frutas indigenas, S. Paulo. Instituto de Bo. tânica. $88 p$.

HUBER, J.

1904 - Notas sobre a Pátria e distribuição geográfica das árvores frutíferas do Pará. B. Mus. Emilio Goeldi, Hist. Nat. Ethnogr., Belém, 4: 375-406 (Apud Cavalcante, 1976)

KERR, W.E.; CLEMENT, C.R.; SILVA FILHO, D.F.

s/d - Práticas de conseqüências genéticas que possibilitavam aos indios da Amazônia uma melhor adaptação, nas condiçōes ecológicas na regiăo (no prelo).
PATIÑO, V.M.

1963 - Plantas Cultivadas y Animales Domésticos en América Equinoccial - tomo I: Frutales. Imprenta Departamental, Cali, Colômbia, $547 p$.

PORTO, P.C.

1936 - Plantas Indigenas e Exóticas provenientes da Amazônia, Cultivadas no Jardim Botânico, Rio de Janeiro. Rodriguesia. Anno II (5) 194p.

PRANCE, G.T. \& SILVA, M.

1975 - Arvores de Manaus. Manaus INPA. 312p. RIBEIRO, M.N.G.

1977 - Boletim Meteorológico Mensal. Instituto Na. cional de Pesquisas da Amazônia. Setor de Meteorologia, Manaus, $14 p$.

(Aceito para publicação em $13 / 03,81$ ) 